\title{
The effect of prior antithyroid drug use on delaying remission in high uptake Graves' disease following radioiodine ablation
}

\author{
Muthiah Subramanian', Manu Kurian Baby ${ }^{2}$ and Krishna G Seshadri ${ }^{3}$ \\ ${ }^{1}$ Department of General Medicine, Sri Ramachandra University, 1 Ramachandra Nagar, Porur, Chennai 600116, India \\ ${ }^{2}$ TB and Pulmonary Medicine, Sri Ramachandra University, 1 Ramachandra Nagar, Porur, Chennai 600116, India \\ ${ }^{3}$ Endocrinology, Diabetes and Metabolism, Sri Ramachandra University, 1 Ramachandra Nagar, Porur, \\ Chennai 600116, India
}

Correspondence should be addressed to K G Seshadri Email

krishnagseshadri@gmail.com

\begin{abstract}
Antithyroid drugs (ATDs) have been shown to attenuate the effectiveness of radioiodine (radioiodine ablation, RIA) therapy in Graves' disease. We undertook a study to look at the impact of iodine uptakes on the outcome of ${ }^{131}$ I therapy. To determine the effect of prior ATD use on the duration of time to achieve cure in patients with high vs intermediate uptake Graves' disease who received a fixed dose $(15 \mathrm{mCi})$ of ${ }^{131}$ I radioiodine. In a retrospective study of patients with Graves' disease, 475 patients who underwent RIA were followed-up on a twomonthly basis with thyroid function tests. Of the 123 patients with a documented preablation RAIU and consistent follow-up it was observed that 40 patients had an intermediate RAIU $(10-30 \%)$ and 83 subjects had a distinctly increased uptake $(>30 \%)$. Successful cure was defined as the elimination of thyrotoxicosis in the form of low free thyroxin and rising TSH levels. When a standard dose of $15 \mathrm{mCi}^{131} \mathrm{I}$ was administered, a cure rate of $93 \%$ was achieved. The median duration of time to cure (TC) was 129 days. Surprisingly, a direct proportional linear relationship $\left(R^{2}=0.92\right)$ was established between time to cure and radioiodine uptake $(\mathrm{TC}>30 \%=172$ days, $\mathrm{TC}_{10-30 \%}=105$ days, $\left.P<0.001\right)$. Patients who used ATD medications took a proportionately longer duration to achieve remission $\left(\mathrm{TC}_{\mathrm{NO}} \mathrm{ATD}=102\right.$ days, $\mathrm{TC}_{\mathrm{ATD}}=253$ days, $\left.P<0.001\right)$. The effect of prior ATD therapy in delaying remission was amplified in the subset of patients with higher uptakes $\left(\mathrm{TC}_{>30}+\mathrm{ATD}=310\right.$ days, $\mathrm{TC}_{>30}+$ NO ATD $=102$ days, $\left.P<0.001\right)$ compared to those with the intermediate uptakes $\left(\mathrm{TC}_{10-30 \%+A T D}=126\right.$ days, $\mathrm{TC}_{10-30} \%+$ NO ATD $=99$ days, $\left.P<0.001\right)$.

RIA, using a dose of $15 \mathrm{mCi}$ achieved a high cure rate. Higher uptakes predicted longer time to achieve remission, with prior ATD use amplifying this effect.
\end{abstract}

\author{
Key Words \\ - ${ }^{131}$ I radioiodine ablation \\ - Graves' disease \\ - antithyroid drug \\ pretreatment \\ - 24-hour radioiodine uptake \\ - remission in Graves' disease
}

\section{Introduction}

Although antithyroid drugs (ATDs) and partial thyroidectomy have established the treatment modalities, radioiodine therapy has become the primary treatment option of hyperthyroidism in Graves' disease $(1,2)$. A number of interrelated factors, such as the use of ATDs, the etiology of hyperthyroidism, the radioiodine dose regimen, the radioiodine uptake (RAIU) and the thyroid volume and mass, influence the successful cure of hyperthyroidism
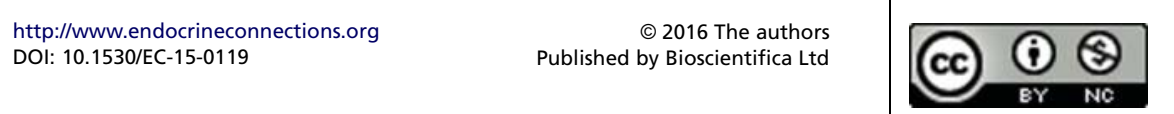
following ${ }^{131}$ I therapy $(3,4,5)$. However, it can be inferred that no single factor reliably predicts the outcome of the therapy.

There is no consensus on the optimal method for determining the ideal ${ }^{131}$ I radioiodine treatment dose. Although some authors advocate the use of adjusted doses based on thyroid gland size, radioactive uptake and effective half-life of ${ }^{131}$ I (iodide turnover), the use of a fixed dose method simplifies the approach with potential cost savings $(6,7,8)$.

The influence of pretreatment with ATDs and 24-h RAIU on the efficacy of radioiodine therapy is controversial. A majority of studies have suggested a reduced cure rate associated with the ATD pretreatment and a higher 24-h thyroid RAIU $(9,10,11,12)$. We undertook a study to evaluate the impact of antithyroid pretreatment on the duration of time needed to achieve cure in patients with the high uptake Graves' thyrotoxicosis who received a fixed dose $(15 \mathrm{mCi})$ of ${ }^{131}$ I radioiodine.

\section{Materials and methods}

\section{Subjects}

We performed a retrospective study of 475 consecutive patients who received initial ${ }^{131}$ I therapy for Graves' disease between January 2010 and December 2012 at Sri Ramachandra Hospital. As suggested by previous authors, the diagnosis of Graves' disease was based on a combination of typical symptoms and signs of hyperthyroidism, suppressed stimulating hormone (TSH), elevated serum thyroid hormones, RAIU, and diffused gland enlargement (clinically or on imaging when performed) (6). A database was constructed and analyzed with respect to the patient characteristics, \% uptake on a pre- ${ }^{131}$ I $24-\mathrm{h}$ RAIU scan, use of ATDs, monthly follow-up thyroid function tests and time taken to achieve a successful outcome. Patients were excluded if they were below 18 years of age, had a 24 -h RAIU less than $10 \%$ or if they had previously undergone treatment for hyperthyroidism and thyroid malignancy in the form of ${ }^{131} \mathrm{I}$ treatment or thyroid surgery. Data were collected from chart review and archival laboratory data, and patients were contacted for missing follow-up information. Of the initial 475 patients, 20 patients did not give verbal consent, and there was no available contact information, documented pre- ${ }^{131}$ I 24 RAIU scan, and monthly follow-up thyroid function test results for 84,89 and 159 patients respectively. Approval for laboratory and clinical review was obtained from the institutional review board of Sri Ramachandra University.

Patients were divided into two groups and categorized as having received ATDs (propylthiouracil (PTU) and methimazole (MMI)), or no therapy prior to ${ }^{131}$ I therapy. Individuals in both groups were further stratified based on their pre- ${ }^{131}$ I 24 h RAIU scan uptake into high uptake and intermediate uptake groups. Intermediate uptake was defined as 24 RAIU of less than $30 \%$ and high uptake as greater than $30 \%$.

\section{Treatment regimen}

A fixed dose of $555 \mathrm{MBq}$ was administered to all patients regardless of prior ATD therapy, size of gland or age of the patients. In those patients who had taken prior ATD, the drug was ceased 5-7 days prior to ${ }^{131}$ I therapy. Patients subsequently attended standardized follow-up with thyroid function test (free thyroxin $\left(\mathrm{FT}_{4}\right)$ and $\mathrm{TSH}$ ) results monthly following the ${ }^{131}$ I therapy. Plasma $\mathrm{FT}_{4}$, TSH and thyroid peroxidase antibodies were measured by Siemens commercial kits according to the manufactures' instructions (Erlangen, Germany).

\section{Outcome after ${ }^{131} \mathrm{I}$ therapy}

The primary outcome of successful therapy was either hypothyroidism or euthyroidism following ${ }^{131}$ I therapy. Hypothyroid patients had a persistent low $\mathrm{FT}_{4}$ and elevated TSH and had been started on levothyroxine replacement. Euthyroidism was defined as normal $\mathrm{FT}_{4}$, TSH levels without levothyroxine. Time taken to achieve successful cure (TC) was defined as the time (in days) from the date of ${ }^{131}$ I therapy to the date of elimination of hyperthyroidism, in the form of euthyroid or hypothyroid thyroid function tests, and expressed as median + interquartile range. Of the 123 patients, 12 patients had treatment failure and had to receive a second dose of radioiodine therapy. Secondary outcomes such as hypothyroidism/euthyroidism developing after a second dose of ${ }^{131}$ I therapy were not considered.

\section{Statistical analysis}

Statistical analysis was performed using SPSS version 15.0. univariate analysis was performed using the $\chi^{2}$ test, MannWhitney $U$ and $\log$ rank tests. Statistical significance was shown with the $P$-value $<0.05$. Logistic regression analysis was used to estimate the strength of relationship among independent variables. A Cox regression was used to

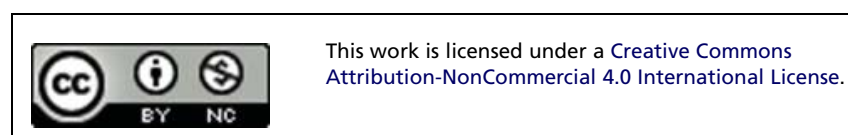


Table 1 Comparison of baseline characteristics of participants and non-participants. All data expressed as mean \pm s.D.

\begin{tabular}{|c|c|c|c|}
\hline Characteristics & Participants & Non-participants & $P$ value \\
\hline Age (years) & $39.40 \pm 12.38$ & $39.71 \pm 10.74$ & 0.790 \\
\hline Sex (males) (\%) & 23.6 & 14.8 & 0.025 \\
\hline 24 h RAIU & $42.60 \pm 15.3$ & $42.07 \pm 12.9$ & 0.979 \\
\hline Received ATD (\%) & $4 \overline{7} .2$ & 43.5 & 0.478 \\
\hline $\mathrm{FT}_{4}{ }^{\mathrm{a}}(\mathrm{ng} / \mathrm{dl})$ & $3.99 \pm 2.21$ & $3.99 \pm 1.92$ & 0.852 \\
\hline $\mathrm{TSH}^{\mathrm{b}}(\mathrm{U} / \mathrm{ml})$ & $0.012 \pm 0.02$ & $0.011 \pm 0.014$ & 0.754 \\
\hline
\end{tabular}

${ }^{\mathrm{a}} \mathrm{FT}_{4}$, free $\mathrm{T}_{4}$ (normal range: $0.8-1.8 \mathrm{ng} / \mathrm{dl}$ ).

${ }^{\mathrm{b}} \mathrm{TSH}$, thyroid-stimulating hormone (normal range: $0.3-4.8 \mathrm{U} / \mathrm{ml}$ ).

determine the association between baseline variables (age, gender, ATD use and $24 \mathrm{~h}$ RAIU) and subsequent duration of time needed to achieve successful cure. The KaplanMeier method was used to study the temporal relationship between prior ATD use, $24 \mathrm{~h}$ RAIU and duration of time for cure.

\section{Results}

Of the potentially eligible 475 subjects, we were able to obtain follow-up of 123 participant patients. The baseline characteristics of the study population and nonparticipants were compared and are summarized in Table 1 . In general, the participants had a higher proportion of males $(P=0.025)$, but were otherwise similar.

Baseline characteristics of the study participants stratified by ATD use and $24 \mathrm{~h}$ RAIU are summarized in Table 2. The average age was 39 years, and there was a female preponderance with a ratio of 3.3:1. The $24 \mathrm{~h}$ RAIU was higher in patients with prior ATD therapy $\left(\mathrm{RAIU}_{\mathrm{ATD}}=\right.$ $\left.46.20 \%, \mathrm{RAIU}_{\mathrm{NO}} \mathrm{ATD}=41.89 \%, P=0.021\right)$. Of the 58 patients who used ATD prior to therapy, 55 individuals (95\%) had received carbimazole and $3(6 \%)$ received PTU. Upon further stratification based on $24 \mathrm{~h}$ RAIU, 84 patients (68\%) had a high-uptake and 37 patients (32\%) had an intermediate uptake.

When a standard dose of $15 \mathrm{mCi}{ }^{131} \mathrm{I}$ was administered, a cure rate (Rc) of 93\% was achieved and the median time taken to achieve cure was 129 days. In comparison to individuals with prior ATD, there was a significant difference in the mean levels of TSH both before (preRIA) and after (post-RIA) radioiodine ablation in those who did not use ATD (pre-RIA TSH $\mathrm{NO}_{\mathrm{ATD}}=0.013$, pre-RIA $\mathrm{TSH}_{\mathrm{ATD}}=0.010, P=0.029$ ), (post-RIA $\mathrm{TSH}_{\mathrm{NO}} \mathrm{ATD}=1.24$, post-RIA $\left.\mathrm{TSH}_{\mathrm{NO}} \mathrm{ATD}=3.83, P=0.031\right)$. A higher cure rate (Rc) was demonstrated in individuals without prior ATD usage. $\left(\mathrm{Rc}_{\mathrm{ATD}}=86 \%, \mathrm{Rc}_{\mathrm{NOATD}}=94 \%, P<0.001\right)$. Patients who used antithyroid medications took a proportionately longer duration to achieve remission $\left(\mathrm{TC}_{\mathrm{NO}} \mathrm{ATD}=\right.$ 102 days, $\mathrm{TC}_{\mathrm{ATD}}=253$ days, $\left.P<0.001\right)$.

The time to achieve cure (TC) was assessed in all patients and is presented as plots for ATD vs NO ATD and high vs intermediate $24 \mathrm{~h}$ RAIU groups (Fig. 1) Regression analysis established a direct proportional linear relationship $\left(R^{2}\right.$ coefficient $\left.=0.92\right)$ between time to cure $(\mathrm{TC})$ and pre- ${ }^{131}$ I $24 \mathrm{~h}$ RAIU scan percentage. Similar direct linear relationships were identified in both patients with and without prior ATD drug usage. $\left(R_{\mathrm{ATD}}^{2}=0.92\right.$, $\left.R_{\text {NOATD }}^{2}=0.95\right)$. An inverse relationship between RAIU

Table 2 Baseline characteristics of the two patient groups with Graves' disease. Continuous variables are expressed as mean \pm s.D.

\begin{tabular}{|c|c|c|c|c|}
\hline \multirow[b]{2}{*}{24 h RAIU } & \multicolumn{2}{|c|}{ Patients who did not use ATD } & \multicolumn{2}{|c|}{ Patients who used ATD } \\
\hline & $10-30 \%$ & $>30 \%$ & $10-30 \%$ & $>30 \%$ \\
\hline Number of patients $(n)$ & 21 & 44 & 16 & 42 \\
\hline Age (years) & $38.12 \pm 13.8$ & $39.07 \pm 12.52$ & $41.48 \pm 13.75$ & $39.29 \pm 10.52$ \\
\hline $\operatorname{Sex}(F: M)$ & $15: 6$ & 33:11 & $14: 2$ & $30: 12$ \\
\hline 24 h RAIU (\%) & $27.06 \pm 9.06$ & $49.14 \pm 10.26$ & $31.65 \pm 12.72$ & $52.77 \pm 9.03$ \\
\hline \multicolumn{5}{|l|}{ Pre-RIA } \\
\hline $\mathrm{TSH}^{\mathrm{b}}(\mathrm{U} / \mathrm{ml})$ & $0.015 \pm 0.003$ & $0.012 \pm 0.037$ & $0.0077 \pm 0.028$ & $0.011 \pm 0.031$ \\
\hline RIA dose $(\mathrm{mCi})$ & 15 & 15 & 15 & 15 \\
\hline \multicolumn{5}{|l|}{ Post-RIA } \\
\hline $\mathrm{FT}_{4}(\mathrm{ng} / \mathrm{dl})$ & $1.17 \pm 0.24$ & $0.804 \pm 0.29$ & $1.61 \pm 0.26$ & $0.71 \pm 0.32$ \\
\hline $\mathrm{TSH}(\mathrm{U} / \mathrm{ml})$ & $1.08 \pm 2.47$ & $1.31 \pm 2.5$ & $8.26 \pm 1.8$ & $2.15 \pm 2.89$ \\
\hline $\begin{array}{l}\text { Time to achieve successful cure } \\
\qquad(\mathrm{TC}, \text { days })^{c}\end{array}$ & $98.5 \pm 36.0$ & $102.0 \pm 64.0$ & $125.5 \pm 43.0$ & $310.0 \pm 238.5$ \\
\hline \multicolumn{5}{|c|}{$\begin{array}{l}{ }^{\mathrm{a}} \mathrm{FT}_{4} \text {, free } \mathrm{T}_{4} \text { (normal range: } 0.8-1.8 \mathrm{ng} / \mathrm{dl} \text { ). } \\
{ }^{\mathrm{b}} \mathrm{TSH} \text {, thyroid-stimulating hormone (normal range: } 0.3-4.8 \mathrm{U} / \mathrm{ml} \text { ). } \\
{ }^{\text {'T }} \text { Time to cure }(\mathrm{TC} \text { ) expressed as median } \pm \text { interquartile range. }\end{array}$} \\
\hline $\begin{array}{l}\text { http://www.endocrineconnections.org } \\
\text { DOI: 10.1530/EC-15-0119 }\end{array}$ & $\begin{array}{r}\text { (c) } 201 \\
\text { Published by Bio }\end{array}$ & & $\begin{array}{l}\text { This work is lice } \\
\text { Attribution-Nor }\end{array}$ & $\begin{array}{l}\text { a Creative Commons } \\
4.0 \text { International License. }\end{array}$ \\
\hline
\end{tabular}



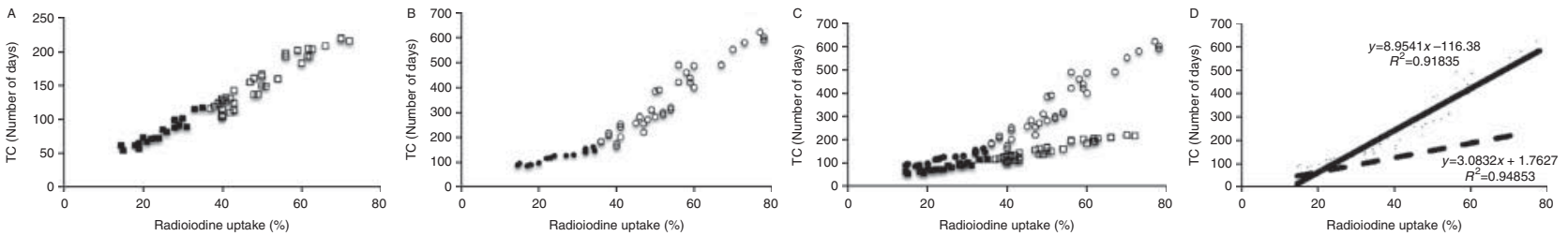

Figure 1

(A and B) Plots for NO ATD and ATD patients with time to achieve cure (TC) respectively. Upon further stratification based on uptake, (C) the amplified effect of ATD in the higher uptake group. Linear regression lines (D), derived from $(C)$, show a directly proportional linear relationship $\left(R_{\text {ATD }}^{2}=0.92, R_{\text {NOATD }}^{2}=0.95\right)$ between radioiodine uptake and duration

and successful outcome was identified, as the intermediate uptake group had a significantly higher cure rate $\left(\mathrm{Rc}_{<30 \%}=95 \%, \mathrm{Rc}_{>30 \%}=90 \%, P<0.001\right)$. The effect of prior ATD therapy in delaying remission was amplified in the subset of patients with higher uptakes $\left(\mathrm{TC}_{>30} \%+\mathrm{ATD}=\right.$ 310 days, $\mathrm{TC}_{>30}+\mathrm{NO}$ ATD $=102$ days, $\left.P<0.001\right)$ compared to those with the intermediate uptakes $\left(\mathrm{TC}_{10-30 \%+\mathrm{ATD}}=\right.$ 126 days. $\mathrm{TC}_{10-30 \%+\text { NO ATD }}=99$ days, $\left.P<0.001\right)$.

On Cox regression analysis, ATD use $(P<0.001)$ was independent predictor of increased duration of time needed to achieve successful remission with a hazard ratio of 4.454 . Age $(P=0.887)$, gender $(P=0.868)$ and $24 \mathrm{~h}$ RAIU $(P=0.822)$ did not significantly predict the duration of time to achieve cure.

Kaplan-Meir survival functions of patients using ATD stratified by RAIU uptake is shown in Figs 2 and 3. The distribution of time to cure was significantly different between those who had prior ATD use and those who did not $(P<0.001$, log-rank test). In patients with the high RAIU, the duration of time to cure was further amplified.

\section{Discussion}

There remains a lack of consensus regarding optimal dose calculation of radioiodine despite widespread use of ${ }^{131} \mathrm{I}$ therapy for patients with Graves's hyperthyroidism. This is due to several factors, including the lack of comprehensive studies and well-designed trials relating the efficacy of different treatment protocols and outcomes (13). In a retrospective analysis of a 100 patients with Graves' thyrotoxicosis, Catargi et al. (14) demonstrated that individualized dosimetry treatment failed in $74 \%$ of patients. Another study, comparing a fixed dose approach with an adjusted dose approach using two radioiodine doses, did not demonstrate any advantage to the adjusted dose method both in terms of efficacy and time to of time needed to achieve cure. Filled square, no ATD, intermediate uptake; open square, no ATD, high uptake; filled circle, ATD, intermediate uptake; open circle, ATD, high uptake; dotted line, no ATD, linear regression; solid line, ATD, linear regression.

outcome (6). Permanent hypothyroidism is an inevitable outcome and therefore the objective of eradicating hyperthyroidism at the lowest effective radioiodine dose may well be the preferred strategy. In our study a fixed dose regimen of $15 \mathrm{mCi}(555 \mathrm{MBq})$ achieved a cure rate of $93 \%$. The results of other studies in evaluation of the efficacy of a similar high dose ${ }^{131}$ I therapy have shown similar results $(15,16)$. Lewis et al. (17) studied 449 patients with hyperthyroidism who had received a standard dose of $550 \mathrm{MBq}$ and found $93.3 \% \quad(74.4 \%$ hypothyroid, $18.9 \%$ euthyroid) were treated effectively by a single dose at 1 year. Due to the logistical reasons some of our patient did not receive a second dose of radioiodine ablation at the end of one year despite not achieving a successful outcome. However long term follow-up revealed that all 16 patients who did not achieve

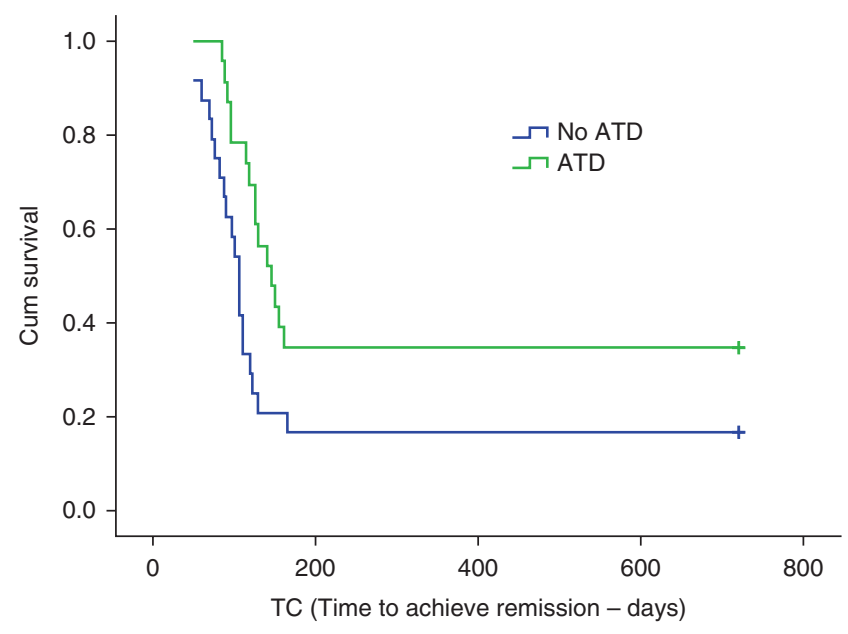

Figure 2

Kaplan-Meier survival functions of patients with intermediate $24 \mathrm{~h}$ RAIU (10-30\%) stratified according to prior ATD use. 


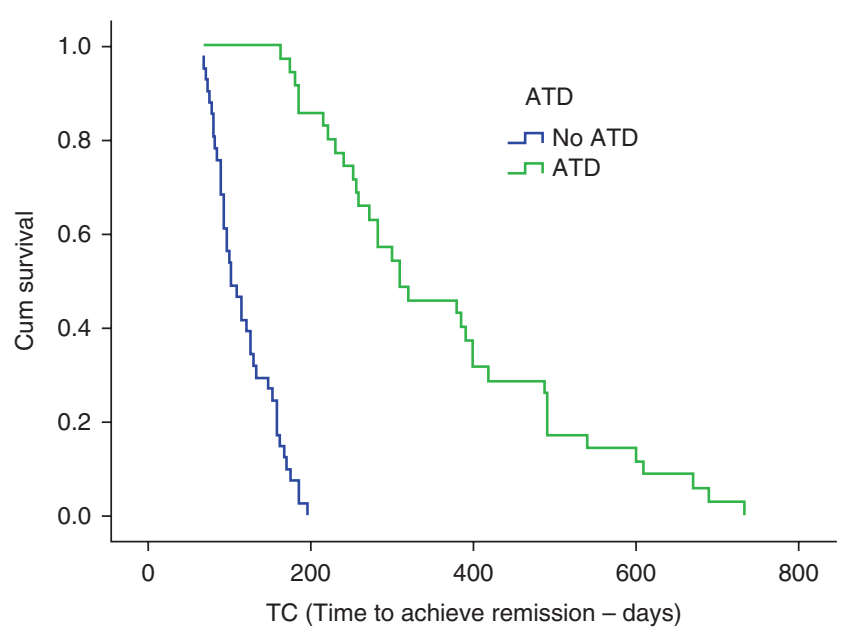

Figure 3

Kaplan-Meier survival functions of patients with high 24 h RAIU (>30\%) stratified according to prior ATD use.

cure at 1 year subsequently attained successful remission within the second year following therapy. A fixed dose of ${ }^{131}$ I $555 \mathrm{MBq}$ is highly effective in the treatment of Graves' hyperthyroidism and further studies relating the long term follow-up of these patients will be essential. The use of a fixed and larger radioiodine dose approach to radioiodine ablation in Graves' disease simplifies the treatment regimen, minimizes the need for retreatment and the potential medical costs with an ineffective primary treatment.

The question of possible interaction of antithyroid medications on the efficacy and outcome of ${ }^{131}$ I radioiodine therapy in Graves' hyperthyroidism remains a controversy. Several studies have demonstrated a decreased efficacy in patients who received a pretreatment with thryostatic medications, although others have confirmed the opposite $(18,19,20,21,22,23)$. As studies differ substantially with respect to design, etiology of hyperthyroidism, regimen of pretreatment with ATD and applied dose of ${ }^{131} \mathrm{I}$, it is difficult to compare their results. In our study, the use of ATDs had a negative impact on successful cure rate and significantly delayed remission. Prior ATD use was found to significantly predict the time to cure even after adjusting for other variables such as age, sex and $24 \mathrm{~h}$ RAIU. Even after delivering a significantly higher dose of ${ }^{131} \mathrm{I}$, Saberi et al. demonstrated that simultaneous thyrostasis was the decisive negative factor against successful ${ }^{131}$ I therapy in Graves' disease (24).

In our study both PTU and MMI were discontinued 5-7 days before therapy. MMI has been shown to influence the ${ }^{131}$ I kinetics by diminishing ${ }^{131}$ I uptake and blocking ${ }^{131}$ I organification resulting in shortened ${ }^{131}$ I effective half-life and reduced adsorbed dose of ${ }^{131} \mathrm{I}(20,25)$. In contrast to our results, Goolden et al. (26) and Marcocci et al. (27) found no interference of MMI with ${ }^{131}$ I therapy when MMI was discontinued 3-5 days, and 5-7 days before ${ }^{131}$ I therapy respectively. Regarding comparability with our study, it is difficult to distinguish between the effects of reduced adsorbed doses and radio protective properties of antithyroid medications as the duration and dosage of pre-treatment was not quantified. The delay in time to cure was significant and can be attributed to the shortened ${ }^{131}$ I half-life and reduced adsorbed dose of ${ }^{131} \mathrm{I}$. Nonetheless, the effects of MMI in our study are not qualitatively different from those of PTU pretreatment.

Several studies have demonstrated a significant relationship between radioiodine therapy and $24 \mathrm{~h}$ RAIU, although the results are contradictory. It has been suggested that the therapeutic effect in patients with a low iodine uptake is much lower than in patients with iodine uptake above $30 \%$, possibly because a low uptake makes radioiodine therapy unfeasible $(7,28)$. In contrast, the results of recent studies patients with the lower pretherapeutic RAI uptakes show the highest success rate after RAI treatment $(11,29,30)$. Our study also found an inverse relationship between pre-treatment iodine uptake and post-treatment successful cure rate when using a fixed dosed of $15 \mathrm{mCi}$. However, when considering time taken to achieve remission, regression analysis revealed a directly proportional linear relationship $\left(R^{2}\right.$ coefficient $=$ 0.92 ) between time to cure and RAIU. In concurrence with our results, Alexander et al. demonstrated that individuals with higher 24-h uptake values are more likely to persist in a hyperthyroid state after 1 year following therapy. There may be several explanations for this observation. The follicular cells could have a biologically different response to higher RAIU in the form of decreased radiosensitivy and high ${ }^{131}$ I turnover rate (31). Thyroid stunning is the phenomenon where the ${ }^{131}$ I uptake by the thyrocyte is attenuated due to prior ionizing radiation. Although measurement of thyroid RAIU requires only little radioactivity compared to thyroid cancer patients, in vitro studies have shown that stunning is associated with decreasing levels of NIS-mRNA and signs of cell cycle arrest $(32,33,34)$. In our study, higher uptakes were associated with a decreased cure rate and relatively longer duration to achieve successful remission.

Multiple authors have suggested the ability of both ATD pretreatment and RAIU in altering ${ }^{131} \mathrm{I}$ bio kinetics and modifying the radiosensitivy of the thyroid follicular

This work is licensed under a Creative Commons Attribution-NonCommercial 4.0 International License. 
cells. Our study found that although $24 \mathrm{~h}$ RAIU did not independently influence time to achieve remission, the effect of prior ATD therapy in delaying remission was amplified in the subset of patients with higher uptakes. This can possibly be explained by the concomitant effect of ATD and higher uptake on shortening ${ }^{131}$ I half-life and reduced adsorbed dose of ${ }^{131}$ I. Another potentially important factor is stunning due to the diagnostic RAIU performed before ${ }^{131}$ I therapy, which in theory has more impact with higher thyroid RAIU.

There are several limitations to our study. The disease severity of Graves' disease was more severe in patients with prior ATD usage, in comparison to those who did use ATD. The other limitations of our study are attributable to a number of additional confounding factors with potential effects on the ${ }^{131}$ I biokinetics, thyroid volume, dosimetry and other aspects of dose calculation. Awaiting more prospective studies it remains speculative whether an altering of the thyroid RAIU achieved by use of ATD leads to a change in efficacy and time to remission in Graves' disease.

In summary, clinical follow-up in patients with Graves' disease treated with a fixed dose of $15 \mathrm{mCi}{ }^{131} \mathrm{I}$ radioiodine ablation therapy was completed. A standard fixed dose of $15 \mathrm{mCi}$ is a highly effective treatment approach that reduces the need for complicated dosimetry calculation and repeated doses of ${ }^{131} \mathrm{I}$ therapy with potential cost savings. ATD pretreatment is a significant negative factor against successful ${ }^{131}$ I therapy; it increases the possibility of treatment failure and delays the duration to achieve successful cure substantially. In a population using iodized salt, prior ATD use predicted longer time to cure, with higher $24 \mathrm{~h}$ RAIU use amplifying this effect. The effect of inherent radio protective properties of ATD in conjunction with 24-h RAIU levels on the successful cure rate of ${ }^{131}$ I therapy awaits further large prospective studies.

\section{Declaration of interest}

The authors declare that there is no conflict of interest that could be perceived as prejudicing the impartiality of the research reported

\section{Funding}

This research did not receive any specific grant from any funding agency in the public, commercial or not-for-profit sector.

\section{Author contribution statement}

Dr M Subramanian and Dr M Kurian Baby contributed in collecting data, data analysis and writing of the manuscript. Prof. K Seshadri's contributed in research concept and design as well as the critical revision of the manuscript.

\section{References}

1 Bahn RS, Burch HB, Cooper DS, Garber JR, Greenlee MC, Klein I, Laurberg P, McDougall IR, Montori VM, Rivkees SA et al. Hyperthyroidism and other causes of thyrotoxicosis: management guidelines of the American Thyroid Association and American Association of Clinical Endocrinologists. Endocrine Practice 201117 456-520. (doi:10.4158/EP.17.3.456)

2 Solomon B, Glinoer D, Lagasse R \& Wartofsky L. Current trends in the management of Graves' disease. Journal of Clinical Endocrinology and Metabolism 199070 1518-1524. (doi:10.1210/jcem-70-6-1518)

3 Bonnema SJ \& Hegedus L. Radioiodine therapy in benign thyroid diseases: effects, side effects, and factors affecting therapeutic outcome. Endocrine Reviews 201233 920-980. (doi:10.1210/er.2012-1030)

4 Šfiligoj D, Gaberšcek S, Mekjavic PJ, Pirnat E \& Zaletel K. Factors influencing the success of radioiodine therapy in patients with Graves' disease. Nuclear Medicine Communications 201536 560-565. (doi:10.1097/MNM.0000000000000285)

5 Willegaignon J, Sapienza MT, Coura-Filho GB, Watanabe T, Traino AC \& Buchpiguel CA. Graves' disease radioiodine-therapy: choosing target absorbed doses for therapy planning. Medical Physics 201441012503. (doi:10.1118/1.4846056)

6 Leslie WD, Ward L, Salamon EA, Ludwig S, Rowe RC \& Cowden EA. A randomized comparison of radioiodine doses in Graves hyperthyroidism. Journal of Clinical Endocrinology and Metabolism 2003 88 978-983. (doi:10.1210/jc.2002-020805)

7 Nordyke RA \& Gilbert FI Jr. Optimal iodine-131 dose for eliminating hyperthyroidism in Graves' disease. Journal of Nuclear Medicine 199132 411-416.

8 Jarlov AE, Hegedus L, Kristensen LO, Nygaard B \& Hansen JM. Is calculation of the dose in radioiodine therapy of hyperthyroidism worth while? Clinical Endocrinology 199543 325-329. (doi:10.1111/j. 1365-2265.1995.tb02039.x)

9 Franklyn JA, Daykin J, Drolc Z, Farmer M \& Sheppard MC. Long-term follow-up of treatment of thyrotoxicosis by three different methods. Clinical Endocrinology 199134 71-76. (doi:10.1111/j.1365-2265.1991. tb01738.x)

10 Tuttle RM, Patience T \& Budd S. Treatment with propylthiouracil before radioactive iodine therapy is associated with a higher treatment failure rate than therapy with radioactive iodine alone in Graves' disease. Thyroid 19955 243-247. (doi:10.1089/thy.1995.5.243)

11 Walter MA, Christ-Crain M, Eckard B, Schindler C, Nitzsche EU, Muller-Brand J \& Muller B. Radioiodine therapy in hyperthyroidism: inverse correlation of pretherapeutic iodine uptake level and posttherapeutic outcome. European Journal of Clinical Investigation 200434 365-370. (doi:10.1111/j.1365-2362.2004.01349.x)

12 Kristoffersen US, Hesse B, Rasmussen AK \& Kjaer A. Radioiodine therapy in hyperthyroid disease: poorer outcome in patients with high 24 hours radioiodine uptake. Clinical Physiology and Functional Imaging 200626 167-170. (doi:10.1111/j.1475-097X.2006.00666.x)

13 Shapiro B. Optimization of radioiodine therapy of thyrotoxicosis: what have we learned after 50 years? Journal of Nuclear Medicine 199334 1638-1641.

14 Catargi B, Leprat F, Guyot M, Valli N, Ducassou D \& Tabarin A. Optimized radioiodine therapy of Graves' disease: analysis of the delivered dose and of other possible factors affecting outcome. European Journal of Endocrinology 1999141 117-121. (doi:10.1530/eje.0.1410117)

15 Kendall-Taylor P, Keir MJ \& Ross WM. Ablative radioiodine therapy for hyperthyroidism: long term follow up study. British Medical Journal 1984289 361-363. (doi:10.1136/bmj.289.6441.361)

16 Jaiswal AK, Bal C, Damle NA, Ballal S, Goswami R, Hari S \& Kumar P. Comparison of clinical outcome after a fixed dose versus dosimetrybased radioiodine treatment of Graves' disease: Results of a randomized controlled trial in Indian population. Indian Journal of Endocrinology and Metabolism 201418 648-654. (doi:10.4103/2230-8210.139222) 
17 Lewis A, Atkinson B, Bell P, Courtney H, McCance D, Mullan K \& Hunter S. Outcome of 131I therapy in hyperthyroidism using a 550MBq fixed dose regimen. Ulster Medical Journal 201382 85-88.

18 Franklyn JA, Daykin J, Holder R \& Sheppard MC. Radioiodine therapy compared in patients with toxic nodular or Graves' hyperthyroidism. QJM 199588 175-180.

19 Koroscil TM. Thionamides alter the efficacy of radioiodine treatment in patients with Graves' disease. Southern Medical Journal 199588 831-836. (doi:10.1097/00007611-199508000-00007)

20 Kung AW, Yau CC \& Cheng AC. The action of methimazole and 1-thyroxine in radioiodine therapy: a prospective study on the incidence of hypothyroidism. Thyroid 19955 7-12 (doi:10.1089/thy.1995.5.7)

21 El Refaei SM \& Shawkat W. Long-term carbimazole intake does not affect success rate of radioactive 131Iodine in treatment of Graves' hyperthyroidism. Nuclear Medicine Communications 200829 642-648. (doi:10.1097/MNM.0b013e3282fda205)

22 Karyampudi A, Hamide A, Halanaik D, Sahoo JP \& Kamalanathan S. Radioiodine therapy in patients with Graves' disease and the effects of prior carbimazole therapy. Indian Journal of Endocrinology and Metabolism 201418 688-693. (doi:10.4103/2230-8210.139234)

23 Saeedinia S, BiBi H \& Pour S. Long-term follow-up for the results of the treatment with anti-thyroid drugs, radioactive iodine and surgery in patients with Graves, disease. Jentashapir Journal of Health Research 2013 4 417-423.

24 Sabri O, Zimny M, Schulz G, Schreckenberger M, Reinartz P, Willmes K \& Buell U. Success rate of radioiodine therapy in Graves' disease: the influence of thyrostatic medication. Journal of Clinical Endocrinology and Metabolism 199984 1229-1233. (doi:10.1210/jcem.84.4.5588)

25 Andrade VA, Gross JL \& Maia AL. The effect of methimazole pretreatment on the efficacy of radioactive iodine therapy in Graves' hyperthyroidism: one-year follow-up of a prospective, randomized study. Journal of Clinical Endocrinology and Metabolism 200186 3488-3493.
26 Goolden AW \& Fraser TR. Effect of pretreatment with carbimazole in patients with thyrotoxicosis subsequently treated with radioactive iodine. British Medical Journal 19693 443-444. (doi:10.1136/bmj.3. 5668.443)

27 Marcocci C, Gianchecchi D, Masini I, Golia F, Ceccarelli C, Bracci E, Fenzi GF \& Pinchera A. A reappraisal of the role of methimazole and other factors on the efficacy and outcome of radioiodine therapy of Graves' hyperthyroidism. Journal of Endocrinological Investigation 1990 13 513-520. (doi:10.1007/BF03348615)

28 Bogazzi F, Bartalena L, Gasperi M, Braverman LE \& Martino E. The various effects of amiodarone on thyroid function. Thyroid $2001 \mathbf{1 1}$ 511-519. (doi:10.1089/105072501300176471)

29 Damle N, Bal C, Kumar P, Reddy R \& Virkar D. The predictive role of $24 \mathrm{~h}$ RAIU with respect to the outcome of low fixed dose radioiodine therapy in patients with diffuse toxic goiter. Hormones $2012 \mathbf{1 1}$ 451-457. (doi:10.14310/horm.2002.1377)

30 Ruchala M, Sowinski J, Dolata M, Junik R, Gembicki M \& Skiba A. Radioiodine treatment of hyperthyroidism in patients with low thyroid uptake. Nuclear Medicine Review. Central \& Eastern Europe 20058 28-32.

31 Traino AC, Di Martino F, Lazzeri M \& Stabin MG. Study of the correlation between administered activity and radiation committed dose to the thyroid in 131I therapy of Graves' disease. Radiation Protection Dosimetry 200195 117-124. (doi:10.1093/oxfordjournals. rpd.a006531)

32 Lundh C, Norden MM, Nilsson M \& Forssell-Aronsson E. Reduced iodide transport (stunning) and DNA synthesis in thyrocytes exposed to low absorbed doses from 131I in vitro. Journal of Nuclear Medicine 2007 48 481-486.

33 Morris LF, Waxman AD \& Braunstein GD. Thyroid stunning. Thyroid 200313 333-340. (doi:10.1089/105072503321669802)

34 Meller B, Gaspar E, Deisting W, Czarnocka B, Baehre M \& Wenzel BE. Decreased radioiodine uptake of FRTL-5 cells after (131)I incubation in vitro: molecular biological investigations indicate a cell cycle-dependent pathway. European Journal of Nuclear Medicine and Molecular Imaging 200835 1204-1212. (doi:10.1007/s00259-007-0666-0)

Received in final form 17 December 2015

Accepted 15 January 2016 http://www.endocrineconnections.org DOI: 10.1530/EC-15-0119
(C) 2016 The authors Published by Bioscientifica Ltd
This work is licensed under a Creative Commons Attribution-NonCommercial 4.0 International License. 